\title{
Histórico da febre amarela no Brasil e a importância da vacinação antiamarílica
}

Historical of yellow fever in Brazil and the importance of vaccination

Karla Vanessa Ferreira' ${ }^{1}$ Katya Cristina Rocha² ${ }^{2}$ Luciana Zambeli Caputto' ${ }^{1}$ Alexandre Luiz Affonso Fonseca', Fernando Luiz Affonso Fonseca ${ }^{3}$

\section{Resumo}

A febre amarela (FA) é um dos maiores desafios para as autoridades de saúde pública por se tratar de uma zoonose e, portanto, de difícil erradicação. Trata-se de uma doença infecciosa não contagiosa de curta duração causada por um vírus. Existem duas formas da doença: a febre amarela urbana (FAU) e a febre amarela silvestre (FAS), tendo como vetores os gêneros Aedes e Haemagogus, respectivamente. Tanto a FAU como a FAS podem variar de assintomática a grave. A principal medida de controle da infecção, após o controle dos vetores, foi realizada através da vacinação com a cepa 17D. A vacina é constituída por vírus atenuado e é efetiva contra a reinfecção pelos vírus selvagens, confere imunidade por, pelo menos, dez anos, e não é recomendada a imunossuprimidos. 0 mecanismo protetor desencadeado pela vacina está associado à produção de anticorpos neutralizantes, ativação de $\operatorname{TCD}^{+}$e adequada integração entre as imunidades inata e adaptativa. A vacinação tem importância na prevenção e controle da doença, já que interrompe o ciclo de transmissão da forma silvestre para a forma urbana através da geração de uma barreira de imunidade coletiva. Tendo em vista que a vacina da FA, apesar de ser altamente segura, vem apresentando um crescente número de relatos de reações adversas graves pós-vacinais, faz-se necessário 0 aumento das investigações acerca da segurança do vírus vacinal 17D, particularmente quando se identifica que diferentes mecanismos podem influenciar o potencial protetor da vacina em hospedeiros considerados imunocompetentes e determinar maior ou menor potencial reatogênico.

Palavras-chave: Cobertura vacinal; febre amarela; Aedes; controle de vetores.

\begin{abstract}
The yellow fever (YF) is one of the biggest challenges to public health authorities, because it is a zoonosis and, therefore, it is difficult to be eradicated. YF is a non-contagious infectious disease of short duration caused by a virus. There are two forms of the disease: the urban yellow fever (UYF) and wild yellow fever (WYF), with main vectors Aedes genera and Haemagogus genera, respectively. Regarding pathogenesis, both forms of the disease may vary from asymptomatic to severe. The main measure of control of infection, after the vector control, was performed by vaccination with the $17 \mathrm{D}$ strain. This vaccine consists in attenuated virus and it is effective against re-infection by wild viruses; it confers immunity for, at least, 10 years, and is not recommended for immunocompromised patients. The main protective mechanism triggered by the vaccine is associated with the production of neutralizing antibodies, potent inducer of TCD4+ activation and proper integration between the innate and adaptive immunity. Vaccination is very important to prevent and control the disease, since it breaks the cycle of transmission from wild forms to the urban forms by generating a barrier of herd immunity. Once the YF vaccine with a high level of security has been showing an increase number of severe adverse reactions, it is necessary to improve the investigations about the security of the vaccine, particularly when it is indentified that different mechanisms of the immunity can influence the immunogenicity and reactogenicity of the vaccine in hosts considered immunocompetent.
\end{abstract}

Keywords: Immunization coverage; yellow fever; Aedes; vector control.

Recebido: $31 / 3 / 2010$

Revisado: $20 / 8 / 2010$

Aprovado: $17 / 1 / 2011$

\footnotetext{
Trabalho realizado na Faculdade de Medicina do ABC (FMABC), Santo André (SP), Brasil

1 Curso de Especialização em Análises Clínicas do Instituto de Pesquisa e Ensino de São Paulo (IPESSP), São Paulo (SP), Brasil

2 Disciplina de Microbiologia e Imunologia da FMABC, Santo André (SP), Brasil

${ }^{3}$ Curso de Ciências Farmacêuticas da FMABC, Santo André (SP); Universidade Federal de São Paulo (UNIFESP), Diadema (SP), Brasil

Endereço para correspondência: Katya Cristina Rocha - Departamento de Patologia - Avenida Lauro Gomes, 2.000 - CEP $09060-870$ - Santo André

(SP) - E-mail: katyarocha20@yahoo.com.br
} 


\section{Introdução}

A febre amarela, que foi o principal problema de saúde pública na segunda metade do século $19^{1}$, é uma doença infecciosa não contagiosa, causada por um arbovírus do gênero Flavivirus ${ }^{2,3}$ pertencente à família Flaviridae. Trata-se de um vírus detentor de apenas um sorotipo, do qual as variações genéticas identificadas na América e na África não apresentam correlação com a gravidade da doença $a^{4}$.

A doença ocorre principalmente no continente africano, onde se concentram mais de $90 \%$ das notificações anuais. No continente americano, as áreas de maior incidência de febre amarela concentram-se no Peru, Bolívia, Colômbia, Equador Venezuela e Brasil ${ }^{4}$.

No Brasil, o vírus da febre amarela está presente principalmente nas regiões Norte e Centro-Oeste, e na parte pré-amazônica do Maranhão, sendo estas regiões endêmicas, com uma população sob risco de, aproximadamente, 30 milhões de pessoas ${ }^{3,4}$. Na região Sul e nos Estados de Minas Gerais e São Paulo, a circulação do vírus é limitada, sendo esta área denominada de área de transição ou epizoótica ${ }^{4}$. Esta faixa foi ampliada e atualmente abrange também áreas do Piauí e da Bahia ${ }^{4,5}$. A ampliação da zona epizoótica tem sido motivo de grande preocupação para as áreas de saúde pública, uma vez que, à medida que se ampliam essas zonas, aumentam as chances da reinstalação da febre amarela urbana, particularmente em associação com a presença do Aedes aegypti, vetor da doença urbana.

A transmissão da febre amarela ao homem se dá pela picada do mosquito da família Culicidae, sendo a espécie Aedes aegypti o principal vetor da febre amarela urbana e o Haemagogus, o principal vetor da febre amarela silvestre 2 . Dentre as diversas espécies de Haemagogus envolvidas na transmissão da febre amarela silvestre, o principal transmissor do vírus no Brasil é o Hemagogus janthinomys, considerado altamente susceptível à infecção, com hábitos silvestres e possui, como principal fonte de alimento, os primatas não humanos (ex: sagui) e, secundariamente, a espécie humana ${ }^{4,6}$. Os mosquitos, além de serem transmissores, são os reservatórios do vírus; uma vez infectados, assim permanecem por toda sua vida, ao contrário dos macacos, que, como os homens, ao se infectarem morrem ou se curam e ficam imunes. Assim, os macacos atuam somente como hospedeiros amplificadores da doença?

\section{Patogenia}

Em relação à patogenia, as infecções urbana e silvestre podem apresentar-se nas formas assintomática, oligossintomática, moderada ou grave. A letalidade global é baixa para esta doença, variando entre 5 a $10 \%$; porém, entre os casos mais graves, pode chegar a $50 \%$, particularmente no Brasil ${ }^{3,4,6}$. Os pacientes mais acometidos geralmente são do sexo masculino, que realizam atividades na zona rural e aqueles que adentram as florestas sem terem sido vacinados ${ }^{3}$. As formas consideradas frustas da infecção podem ser mais frequentemente ob- servadas em crianças de baixa idade, filhas de mães vacinadas e em populações indígenas ${ }^{8}$.

O caminho percorrido pelo vírus, após atingir o organismo do hospedeiro pela picada do transmissor, é sua chegada nos linfonodos regionais, onde irá se replicar em linfócitos e macrófagos, desaparecendo, assim, da circulação por 24 horas. Após realizar seu ciclo replicativo, as partículas virais deixam as células e caem na corrente linfática até atingirem a corrente sanguínea, caracterizando o período de viremia e atingindo finalmente o fígado. Este é o principal órgão acometido na febre amarela, onde as células de Kupffer e os hepatócitos são infectados ${ }^{3,6,7}$. Neste período, o indivíduo apresenta febre e o sangue torna-se infectante para os vetores não infectados?.

Não se conhecem todos os mecanismos responsáveis pela patogenia do vírus amarílico em humanos, uma vez que grande parte do conhecimento é derivada de informações obtidas em estudos realizados com primatas não humanos, hamsters e camundongos ${ }^{8}$. Em humanos, os achados histológicos são derivados, na sua maioria, de necropsias e assemelham-se muito aos encontrados em primatas não humanos. Em geral, os sintomas nas formas leves se restringem a febre baixa ou moderada, com a presença de cefaleia discreta e indisposição passageira. Já nas formas moderadas (normalmente caracterizada por quadros mais arrastados), o paciente também pode apresentar náuseas sem vômitos, assim como mialgias e artralgias leves, cefaleia e febre mais duradoura. Além desses sintomas, ainda aparece pelo menos um dos sintomas clássicos da doença: hematêmese (vômito com sangue), icterícia (a pele e os olhos ficam amarelos) ou oligúria. Neste caso, a recuperação também é completa, sem danos aos pacientes ${ }^{2,4,6}$.

$\mathrm{Na}$ forma maligna da febre amarela, os pacientes sempre apresentam os três sintomas clássicos que caracterizam a falência hepatorrenal com bilirrubina e aminotransferases muito elevadas e aumento não muito pronunciado de ureia e creatinina. $O$ quadro evolui em duas fases, com um período de remissão entre as mesmas. A sintomatologia da forma clássica maligna da doença caracteriza-se pelo início abrupto, surge febre elevada sem elevação da pulsação e cefaleia holocraniana intensa durante 2 a 3 dias. Em muitos pacientes, seguindo-se a esta fase, há o período que se caracteriza por sensação de melhora, em que se observa diminuição da febre, das dores musculares e da cefaleia. O período de remissão costuma durar de algumas horas até 1-2 dias; em seguida, ao contrário dos indivíduos que desenvolvem as formas leve, moderada e grave que realmente se curam, esses pacientes apresentam súbita piora do quadro; inicia-se, então, o período toxêmico em que o vírus deixa de circular no sangue, sendo encontrado, principalmente, no fígado e baço, além do coração, linfonodos e outros órgãos. As náuseas intensificam-se e os vômitos agravam-se. Outras manifestações hemorrágicas são também usualmente encontradas, como, por exemplo, as hemorragias do tegumento, das gengivas e melena ${ }^{8}$.

Acompanhando ou mesmo antecedendo as hemorragias, há plaquetopenia, por vezes responsável pelo óbito. Nem sempre a gra- 
vidade da hemorragia associa-se ao número de plaquetas, mas aos problemas ligados à ativação do complemento e ao consumo dos fatores de coagulação, indicando que, na febre amarela, há coagulação intravascular disseminada. Em casos graves, pode-se identificar grande variedade de alterações sanguíneas, como: diminuição dos fatores de coagulação, do tempo de sangramento, de protrombina, e presença de produtos degradados da fibrina que, em conjunto, sugerem que a febre amarela evolui com coagulopatia de consumo e coagulação intravascular disseminada ${ }^{8-11}$.

A fim de esclarecer os mecanismos lesivos hepáticos desencadeados na infecção com vírus da febre amarela, Quaresma et al. ${ }^{12}$ demonstraram que múltiplos são os fatores responsáveis pela lesão dos hepatócitos no curso da doença, entre eles, o efeito citopático direto do vírus, a ação direta de células TCD4 ${ }^{+}$e $\mathrm{TCD} 8^{+}$, bem como a produção de citocinas (Transforming Growth factor beta-TGF- $\beta$, Interferon gama- IFN- $\gamma$ e Tumor Necrosis Factor alfa-TNF- $\alpha$ ), capazes de promover alterações hepáticas vasculares que contribuem fortemente para a imunopatogênese da febre amarela. Em outro estudo realizado pelo mesmo autor ${ }^{13}$, foi possível identificar, em cortes histológicos de casos fatais de febre amarela, que, além da lesão hepática inflamatória desencadeada pela infecção, a destruição dos hepatócitos, das células de Kupffer e de células inflamatórias mononucleares ao longo da doença é provocada, em grande parte, por mecanismos apoptóticos não inflamatórios. De acordo com os autores, as células NK (Natural Killer) e os LTCD $8^{+}$determinam a apoptose das células infectadas e participam, assim, da imunopatogênese da doença. Além da ação apoptótica destas células, a participação de $\operatorname{LTCD} 4^{+}$subpopulação Th3 parece contribuir fortemente para que a lesão hepática tenha um caráter não inflamatório e pró-apoptótico, uma vez que a produção aumentada de TGF- $\beta$ é capaz de controlar negativamente a inflamação provocada por células mononucleares e induzir, concomitantemente, a apoptose celular ${ }^{14}$.

\section{Panorama histórico}

O primeiro relato de epidemia de uma doença semelhante à febre amarela é de um manuscrito Maia de 1648 em Yucatán, México. Na Europa, a doença já havia se manifestado antes dos anos 1700, mas foi em 1730, na Península Ibérica, que se deu a primeira epidemia, causando inúmeras mortes ${ }^{1,4}$.

Os Estados Unidos foram acometidos pela doença nos séculos 17 e 19, com epidemias devastadoras ${ }^{1}$. Na África, essa doença foi relatada desde antes de seu descobrimento, sendo provavelmente a responsável pela disseminação no Brasil, no final do século $17^{9}$. Na região do Caribe, foram descritas 83 epidemias de 1620 a 1900. Nos arredores de Havana (Cuba), o vírus permaneceu em atividade desde 1762 até o início do século 20, quando Gorgas conduziu a erradicação do vetor ${ }^{1}$.

No Brasil, a febre amarela surgiu no final do século 17; desde então, essa doença tornou-se a principal moléstia epidêmica do país ${ }^{15}$.
Durante o período colonial, o país sofreu com sucessivas epidemias: em 1685, surgiram epidemias em Olinda e em outras cidades de Pernambuco, além de um grande surto na Bahia, em $1686^{15}$.

A epidemia que irrompeu em meados do século 19 na capital do Império brasileiro foi atribuída à chegada de um navio negreiro procedente de Nova Orleans, tendo feito escalas em Havana e Salvador antes de atracar no Rio de Janeiro, em dezembro de 1849. Fato relevante, que foi decisivo para o desenvolvimento da epidemia, foi a instalação do Aedes aegypti na cidade do Rio de Janeiro. Em fevereiro de 1850, a febre amarela se apossara da cidade e das praias da região. Segundo estimativa, atingiu 90.658 habitantes do Rio de Janeiro, causando 4.160 mortes, de acordo com os dados oficiais. Foi então constituída a Junta de Higiene Pública, que, em 1886, transformou-se em Inspetoria Geral de Higiene e Inspetoria Geral de Saúde dos Portos ${ }^{16}$.

As epidemias de febre amarela aconteciam com regularidade na estação de calor e chuvas. Os higienistas iniciaram então um programa, que contemplava amplo repertório de ações destinadas a reformar tanto a paisagem natural da cidade como práticas e hábitos de seus moradores. Os debates sobre a urgência de sanear o Rio de Janeiro aumentaram entre duas epidemias violentas de febre amarela (1873 e 1876) que causaram, respectivamente, 3.659 e 3.476 óbitos. O saneamento do solo e a drenagem do subsolo do Rio de Janeiro foram, assim, as medidas consideradas mais urgentes para sanear a capital brasileira ${ }^{16}$.

Posteriormente, São Paulo foi atingida por uma epidemia de febre amarela, especificamente na cidade de Santos, que era considerada porta de entrada de imigrantes, os quais traziam a doença que, a partir daí, se alastrava ${ }^{15}$.

Várias teorias surgiram para explicar a transmissão da doença. Muitos achavam que se tratava de uma doença contagiosa; já outros acreditavam que se tratava de uma doença transmissível ou infecciosa que necessitava de um agente que a transportasse de uma pessoa doente para outra sã. As controvérsias sobre a etiologia e profilaxia da febre amarela apenas tiveram fim a partir de um deslocamento radical na abordagem da doença que levou a nova geração de bacteriologistas para o proscênio da saúde pública, sob a liderança de Oswaldo Cruz ${ }^{15,17}$.

A febre amarela passou a ser estudada sob os paradigmas da microbiologia e, a partir de então, várias hipóteses foram levantadas sobre o micro-organismo causador da doença. Finalmente, em 1927, médicos da Fundação Rockefeller, trabalhando com macacos, descobriram que o agente causador da febre amarela é um vírus ${ }^{1,15}$.

Após a descoberta do agente infeccioso causal, os pesquisadores passaram, então, a investir na produção de uma vacina e, em 1937, a Fundação Rockefeller passou a produzir a vacina contra febre amarela em larga escala ${ }^{15}$.

Em 1848, foi Nott quem primeiro aventou a hipótese de que a febre amarela era transmitida por mosquito, mas foi o médico francês Louis Daniel Beauperthuy que, em 1854, relatou os fatos acerca da transmissão da febre amarela em artigo publicado no jornal "Gaceta Oficial de Cumana”, Venezuela. Quase três décadas após, em 1881, Carlos Finlay 
defendeu a mesma teoria proposta por seu antecessor e apontou o Aedes aegypti como vetor. Foi Walter Reed quem comprovou, pela primeira vez em 1901, que a transmissão da Febre Amarela ocorria por intermédio de um vetor ${ }^{1}$. Em 1938, pesquisadores conseguiram associar o mosquito Haemagogus com a transmissão da febre amarela silvestre ${ }^{1}$.

Em 1986, outro vetor, o Aedes albopictus, foi identificado no Brasil, atingindo vários estados. Esse mosquito é considerado um vetor potencial da febre amarela silvestre ${ }^{1}$.

O trabalho de combate até o controle da febre amarela urbana, no Brasil, durou mais de 50 anos. Entre os responsáveis pelo processo, poderia ser citado o médico Emílio Marcondes Ribas, que antecedeu Oswaldo Cruz no combate ao vetor transmissor da doença ${ }^{1}$. Foi a partir de 1903, quando Oswaldo Cruz foi nomeado Diretor Geral de Saúde Pública, que foi criado o Serviço de Profilaxia da febre amarela. Foram quase 50 anos de luta para que, em 1942, fossem notificados os últimos casos de febre amarela urbana no Brasi $1^{17}$.

Até pouco tempo, grande parte da América do Sul estava livre do vetor da febre amarela urbana. Foi na década de 1970 que o A. aegypti voltou a infestar seu antigo território. Esta mudança, somada à crescente migração humana dentro e fora da zona endêmica, aumentou muito o risco de reaparição da doença urbana em toda a América do Sul. Caso isto ocorra, haverá um aumento da probabilidade de exportação de humanos virêmicos para zonas receptoras distantes onde se encontra o vetor urbano (Caribe, América Central, do Norte, Ásia e Austrália) ${ }^{18}$.

\section{Vacina antiamarílica}

A febre amarela é uma doença de notificação obrigatória e, por isso, qualquer caso suspeito deve ser imediatamente notificado à autoridade sanitária local, estadual ou nacional, e esta deve notificar os órgãos internacionais ${ }^{5,8}$.

Como não há tratamento antiviral específico para o vírus da febre amarela ${ }^{6}$, a principal medida para prevenir a infecção pelo mesmo é através da vacinação com a amostra $17 \mathrm{D}^{8}$.

Essa vacina, produzida no Brasil desde 1937, primeiramente pelo Instituto Oswaldo Cruz e, posteriormente, pelo Instituto de Tecnologia em Imunobiológicos Bio-Manguinhos, é constituída por vírus atenuados derivados de uma amostra africana do vírus amarílico selvagem, denominada Asibi. A linhagem 17D é cultivada em ovos embrionados de galinha ${ }^{5,19}$.

$\mathrm{O}$ vírus da febre amarela pode ser inativado por solventes lipídicos (éter, clorofórmio) e/ou aquecido a $56^{\circ} \mathrm{C}$ por 30 minutos sob luz ultravioleta. A vacina 17D é efetiva contra todos os genótipos de vírus da febre amarela, nos dois continentes ${ }^{20}$. O vírus da vacina 17D difere de seu progenitor selvagem em 31 mutações, o que representa uma mudança próxima de $0,8 \%$. A base molecular que precisa a atenuação não é completamente conhecida, mas é, sem dúvida, multigênica. Existem sete fabricantes da vacina em todo o mundo, mas somente três, Brasil, França e Senegal, produzem quantidades suficientes para serem utilizadas no Programa de Imunização Estendido (Expanded Program Immunization - EPI) ou em vacinações de emergência ${ }^{18}$.

A vacina apresenta-se sob a forma liofilizada em frasco-ampola de 50, 10 e 5 doses, acompanhada de diluente. Cada frasco-ampola deve trazer o número do lote e a validade ${ }^{1}$.

A produção da vacina permitiu pela primeira vez o seu uso em maior escala durante o surto epidêmico de febre amarela ocorrido no município de Varginha (MG). Posteriormente, foi utilizada em programas de vacinação em outros estados brasileiros, com grande sucesso'.

A Organização Mundial de Saúde (OMS) recomenda a vacinação a todas as crianças maiores de seis meses, que vivam em áreas endêmicas, ou que se dirijam a elas ${ }^{8}$. Esta vacina confere proteção entre o sétimo e décimo dia após a aplicação, período no qual aparecem os anticorpos protetores e razão pela qual a imunização deve ocorrer dez dias antes de se ingressar em área de transmissão. A vacina confere imunidade por, aproximadamente, 10 anos, podendo, em alguns casos, uma única dose proteger por mais de três décadas ${ }^{5,21}$.

Estudos realizados mostram que $97,1 \%$ das pessoas vacinadas têm anticorpos protetores contra o vírus após 18 anos $^{1,22,23}$.

A efetividade da vacina 17D, em atuação no Brasil, foi avaliada no início de sua utilização, durante as décadas de 1930 e 1940, onde se estabeleceram dois critérios para a avaliação:

- $\quad$ verificação de anticorpos protetores em $95 \%$ ou mais das pessoas vacinadas $^{22}$;

- interrupção de epidemias de febre amarela silvestre após a vacinação ${ }^{23}$.

A vacina foi testada de acordo com as condições utilizadas pelos serviços de saúde pública ${ }^{16}$. Assim, para avaliar a efetividade da mesma, devem-se levar em conta as possíveis condições de armazenamento, transporte, manipulação e aplicação ${ }^{22-24}$.

Em análise temporal (1930-1997), representativa dos casos de febre amarela versus cobertura vacinal, fica evidenciada a ocorrência cíclica de surtos de febre amarela a cada cinco anos. As intervenções pontuais realizadas através do aumento da cobertura vacinal propiciaram um decréscimo progressivo do número de casos de febre amarela, que acabou por determinar a erradicação da forma urbana da doença como resultado de uma barreira de imunidade coletiva na população em risco ${ }^{1}$. Assim, a fim de se controlarem os surtos de febre amarela silvestre e urbana, recomenda-se a vacinação nos municípios, de acordo com sua prioridade.

Desde 1988, a OMS tem reiterado a recomendação para que seja incorporada ao Programa de Imunização Estendido (EPI) a vacina da febre amarela e, nos últimos dois anos, a Bill and Melinda Gates Foundation tem apoiado a compra de vacinas para este fim. Apesar destas iniciativas, a cobertura vacinal é ainda muito baixa (inferior a 50\%) em quase todos os países da África. Já na América do Sul, a incidência da febre amarela é menor devido a uma maior cobertura vacinal e a uma menor densidade populacional nas zonas endêmicas ${ }^{18}$. 
Os municípios com maior prioridade são aqueles de área endêmica e de transição para febre amarela silvestre com Aedes aegypti; em seguida, estão os municípios da área endêmica e de transição para febre amarela silvestre sem Aedes aegypti; a terceira área corresponde a municípios de área indene para febre amarela silvestre com infestação domiciliar de Aedes aegypti; e a área com menor prioridade corresponde a município de área indene para febre amarela silvestre sem infestação de Aedes aegypti ${ }^{1,6}$.

Além da vacinação, outro procedimento de grande eficácia para o controle da febre amarela urbana é o extermínio do vetor. Na prática, porém, devido ao grande crescimento dos centros urbanos, torna-se quase inviável a eliminação do mosquito Aedes aegypti, sendo mais eficaz a tomada de medidas de proteção individual, tais como: uso de repelentes, tela nas janelas e cuidados para evitar a proliferação do mosquito, como impedir a formação de água parada nos recipientes domiciliares $^{8}$.

\section{Resposta imune do hospedeiro após imunização com a cepa 17D}

A vacina $17 \mathrm{D}$ é capaz de induzir imunidade em $95 \%$ dos vacinados, em um período de 10 dias, e contra todos os genótipos virais selvagens ( 7 variantes que diferem genotipicamente em cerca de 25,1 e $7,9 \%$ quanto à expressão proteica). A vacina $17 \mathrm{D}$ induz rapidamente a formação de resposta humoral específica. Dentro de 3 a 7 dias pós vacinação, já se pode detectar a presença de anticorpos IgM que atingem seu pico ao redor de duas semanas e declinam vagarosamente por meses. Anticorpos IgG são detectados 7 dias após a aplicação da vacina e podem persistir por até 45 anos; apesar disto, a OMS recomenda a revacinação após 10 anos, a fim de manter a resposta protetora. Os estudos acerca da imunidade conferida pela vacina 17D apontam que são os anticorpos neutralizantes os responsáveis pela proteção dos hospedeiros expostos à infecção natural e apontam o fator transcricional TNFRSF17 como $100 \%$ preditor da produção de anticorpos neutralizantes contra o vírus $^{25}$. Interessantemente, apesar de anticorpos fixadores de complemento serem detectados após a infecção natural pelo vírus da Febre Amarela, a vacina 17D não é capaz de promover a produção dos mesmos, não sendo, portanto, um mecanismo de proteção para o hospedeiro vacinado ${ }^{25}$. Com relação à indução de resposta adaptativa celular, a vacina 17D é considerada como potente indutora de resposta imune para célula $\mathrm{TCD} 4^{+}$como $\mathrm{TCD} 8^{+}$, particularmente contra proteínas estruturais ${ }^{26,27}$. Em estudo recente acerca dos eventos imunológicos desencadeados após a vacinação com o vírus da febre amarela, Martins et al. ${ }^{26}$ demonstraram que indivíduos saudáveis, quando submetidos à imunização com a cepa 17DD, apresentam inicialmente ativação das células TCD4 ${ }^{+}$(sete dias após imunização), seguida pelas células $\mathrm{CD} 19^{+}$(LB), que são ativadas 15 dias após imunização e, por último, as células TCD8+ (ativadas 30 dias após a imunização) ${ }^{26}$. Segundo os autores, apesar de se observar uma potente ativação de todas as populações linfocitárias (LB, $\mathrm{TCD}^{+}$e TCD $^{+}$), um efeito imunomodulador, tanto da imunidade celular quanto da humoral, foi observado após imunização. Tendo em vista que nenhum dos voluntários submetidos à vacinação desenvolveu eventos adversos, os autores propõem que o aumento do número de célula $\mathrm{T}$ regulatória, o aumento da expressão do receptor Fc $\gamma$ RII e do receptor para IL-10, em LB, e o aumento de HLA DR e CCR2, em LT, podem ser considerados, em conjunto, como "marca registrada" de uma resposta imune protetora e livre de eventos adversos contra o vírus 17DD²6.

Da mesma maneira que a imunidade adaptativa, a imunidade inata também desempenha importante papel, no que diz respeito ao nível e à qualidade da resposta imune pós-vacinal. $\mathrm{O}$ vírus da vacina 17D apresenta baixa capacidade replicativa em células dendríticas; porém, através da sua interação com receptores do tipo Toll 7 e 8 (Toll Like Receptors-TLR), há o desencadeamento da produção de citocinas pró-inflamatórias como IL-lbeta, TNF (Tumor Necrosis Factor) e de interferons do tipo I (IFN alfa e beta) pelas células de sangue periférico (citocinas capazes de desencadear a resposta imune adaptativa com perfil Th1). Já a interação do vírus 17D com os receptores do tipo Toll 2 induz a produção de IL-10 (interleucina 10) e a ativação de células Treg (Células T reguladoras). Desta forma, uma vez que o vírus é capaz de interagir com os receptores tipo Toll 2, 7 e 8, fica claro que a vacinação com o vírus 17D é capaz de promover um balanço entre a produção de citocinas de padrão Th1 (T helper tipo 1) e de padrão Th2 (T helper tipo 2$)^{28}$. De acordo com Santos et al. ${ }^{29}$, a vacinação com a cepa 17D induz a produção de grandes quantidades de interferon gama (IFN- $\gamma$ ) e IL-4 (interleucina 4), sendo ambas citocinas importantes para levarem ao desencadeamento de resposta imune adaptativa humoral e celular. Segundo estes autores, a ativação balanceada das subpopulações Th1 e Th2 seria importante para que o hospedeiro vacinado pudesse desenvolver uma resposta imune eficaz, mas sem apresentar reações adversas pós-vacinais ${ }^{29}$.

Após a realização de estudo fenotípico detalhado das populações celulares de sangue periférico (monócitos, eosinófilos, células NK e células NKT) ativadas pela vacinação com o vírus 17DD, Martins et al..$^{30}$ demonstraram que a imunomodulação exercida por estas células é capaz de desencadear imunidade protetora contra o vírus, bem como é capaz de exercer efeito imunomodulador necessário à prevenção do desenvolvimento de eventos adversos pós-vacinais. $O$ trabalho realizado por estes autores não apenas enfatiza o papel da imunidade inata no desencadeamento da imunidade adaptativa, mas também elucida, brilhantemente, a ação, antes desconsiderada por muitos imunologistas, dos neutrófilos e eosinófilos na imunidade contra agentes infecciosos virais ${ }^{30}$. 


\section{Efeitos adversos associados à vacina 17D}

A vacina 17D tem sido largamente aplicada desde o final da década de 1930, com raros casos de reações adversas graves, pois é desprovida habitualmente de neuro e viscerotropismo ${ }^{31}$. Entretanto, podem ser relatados alguns eventos adversos da vacina, sendo os mais comuns: hipersensibilidade ${ }^{21}$, mal-estar, cefaleia, dores musculares e febre baixa, ocorrendo entre 2 a $5 \%$ dos vacinados, por volta do quinto ao décimo dia. Essas reações duram de um a dois dias ${ }^{20}$.

Alguns casos de reações adversas graves foram descritos nos EUA e Brasil; porém, o pequeno número de casos avaliados e a ampla utilização desta vacina no mundo, associados aos dados de estudos destes casos, apontam para uma predisposição individual ainda não conhecida, muito difícil de ser associada previamente ao uso da vacina ${ }^{5}$.

Como a vacina é obtida através do vírus atenuado da febre amarela, não é recomendada para imunossuprimidos e gestantes. Indivíduos alérgicos à proteína do ovo também não devem ser vacinados ${ }^{5}$. Nesse caso, os pacientes devem, obrigatoriamente, consultar o médico para saber se podem receber a vacina de febre amarela ${ }^{19}$. Essa vacina também é contraindicada para crianças menores de seis meses de idade e indivíduos com doença infecciosa aguda em estado febril ${ }^{19}$, sendo estes susceptíveis a eventos adversos graves, como a encefalite ${ }^{19}$.

Existem dois tipos de evento adverso sério (EAS) associados à vacinação com a cepa 17D: doença neurotrópica associada a vacina (DNAV), causada após invasão neural pelo vírus vacinal, e doença viscerotrópica associada a vacina (DVAV), uma doença muito similar a infecção natural causada pelo vírus selvagem da febre amarela ${ }^{18,25}$. Os casos de DNAV relatados até o momento estiveram fortemente associados à idade dos indivíduos vacinados: crianças menores de seis meses foram as grandes vítimas deste evento adverso. A partir da década de 1950, quando se passou a recomendar a vacinação das crianças somente acima de seis meses, raríssimos foram os casos notificados de DNAV ${ }^{18,26}$.

A DVAV foi pela primeira vez relatada, na literatura mundial, em 2001; desde então, 51 casos foram publicados até maio de 2009. Três foram os fatores de risco apontados para o desenvolvimento deste evento grave: em primeiro lugar, a idade avançada (acima de 60 anos); em segundo lugar, o gênero (mais frequente em homens) e, em terceiro lugar, o histórico de doença tímica que tenha culminado com timectomia ${ }^{18,25}$.

De acordo com extensa revisão da literatura realizada por Hayes $^{32}$ acerca dos mecanismos responsáveis pelo desencadeamento da DVAV, três poderiam ser os possíveis mecanismos responsáveis pelo desenvolvimento deste tipo de reação adversa desencadeada pelo vírus 17D: 1) reversão do vírus, no hospedeiro vacinado, para sua forma selvagem ou para uma forma mais virulenta; 2 ) susceptibilidade genética do hospedeiro vacinado; 3) presença de um agente exógeno ou de um componente vacinal capaz de modular a resposta do hospedeiro. De acordo com as evidências observadas até o momento, nenhuma alteração genética capaz de justificar aumento de virulência foi definitivamente associada nos vírus isolados de indivíduos que apresentaram DVAV; já os fatores idade e/ou presença de doenças tímicas (ex: timectomia) parecem exercer papel mais definitivo na patogênese da $\mathrm{DVAV}^{32}$.

Após estudo realizado por Vasconcelos et al..$^{33}$, em que cepas isoladas de casos humanos de DVAV (de 1935 a 2001) foram genotipadas, foi possível observar que, à exceção de um caso (denominado Brasil 75), todas as cepas isoladas não apresentaram alterações genômicas significativas que pudessem estar associadas à reversão do vírus vacinal para sua forma selvagem ou que os tornassem vírus vacinais mais virulentos, já que todos os vírus isolados foram identificados como vírus selvagem da febre amarela ${ }^{33}$. Já com relação à cepa Brasil $75^{34}$, foi possível identificar que se tratava de um vírus de origem vacinal com importantes alterações genômicas que, possivelmente, influenciaram sua virulência (particularmente em regiões codificadoras para proteínas envolvidas na resistência viral à ação de interferon e localização viral). Os autores acreditam ainda que o número de casos de DVAV deva ser maior que o conhecido, uma vez que a DVAV determina um quadro clínico indistinto dos casos de febre amarela provocada pelo vírus selvagem. Assim, segundo a hipótese dos autores, muitos casos de DVAV devem ter sido erroneamente atribuídos à infecção pelo vírus selvagem e, portanto, não investigados como evento adverso pós-vacinal.

Um vasto campo ainda a ser investigado são os genes do hospedeiro que codificam receptores (ex: genes codificadores dos receptores tipo Toll) e moléculas efetoras envolvidas em mecanismos antivirais (ex: citocinas, oligoadenilato sintetases). Galler et al..$^{35}$, após avaliarem possíveis alterações genéticas em três amostras virais isoladas de humanos, que apresentaram reação adversa grave, após terem sido vacinados para a febre amarela nas cidades de Americana, Goiânia e Santos, concluíram que, pelos métodos empregados, não foi possível identificar alterações genéticas capazes de aumentar a virulência do vírus em nenhum dos casos estudados. Os autores propõem ainda que as reações observadas nos pacientes possam ser consequência de interações biológicas complexas que envolvam o sistema imune adaptativo (linfócitos $\mathrm{T}$ e B), sistema imune inato (interferon tipo I) e o sistema endócrino. Em conjunto, ou separadamente, os três sistemas podem facilitar a replicação viral e/ou aumentar a virulência do vírus, circunstâncias estas que deteminariam maior viremia e lesão do hospedeiro ${ }^{35}$.

A análise do mecanismo imunológico pelo qual o vírus vacinal é capaz de causar doença sistêmica ainda precisa ser mais bem compreendida; porém, alguns estudos têm contribuído para a elucidação de algumas características importantes que corroboram para o entendimento do mecanismo pelo qual se desenvolve a DVAV. Segundo estes estudos, não foram identificados defeitos de reconhecimento por parte dos linfócitos B ou T, as citocinas inflamatórias (IL-8 - interleucina 8, IL-6 - interleucina 6 e MCP - Macrophage Chemotatic Protein) foram identificadas em grandes quantidades após a vacinação e, em 
apenas um caso fatal, foi identificado polimorfismo em um receptor de quimiocina (CCR5) ${ }^{25}$. Por enquanto, os dados disponíveis parecem indicar uma falta de conexão entre as imunidades inata e adaptativa que ainda necessita de investigação. Vale ressaltar que estudo realizado por Mota et al..$^{36}$ apontou que pacientes com diagnóstico de doença reumática, em uso de imunossupressor e vacinados para febre amarela, não apresentaram maiores eventos adversos que os considerados imunocompetentes; o mesmo foi observado em estudo realizado com pacientes HIV positivos.

\section{Considerações finais}

A descoberta de que a Febre Amarela era causada por um vírus e que sua transmissão estava associada à presença de um vetor específico foi decisiva para o início do controle de uma doença que assolou o Brasil a partir do século XVII. Além da reurbanização das cidades, a partir da observação de que as condições higiênicas favoreciam a dispersão da doença (uma vez que a proliferação do vetor é facilitada em condições sanitárias inadequadas), o desenvolvimento da vacina antiamarílica foi decisivo para que, em meados do século 20, a doença urbana fosse eliminada. Tendo em vista a distribuição do vetor e que a urbanização descontrolada atual favorece a proliferação do mesmo, os Centros de Vigilância Epidemiológica devem, continuamente, avaliar potenciais áreas de risco e reavaliar as já conhecidas, com o objetivo de assegurar que medidas de emergência sejam tomadas a fim de se controlar os focos de febre amarela silvestre e evitar o ressurgimento da forma urbana da doença.

Tendo em vista que a vacina da febre amarela, de acordo com os relatos mundiais, apesar de ser considerada altamente segura, vem apresentando um crescente número de relatos de reações adversas graves pós-vacinais, faz-se necessário o aumento das investigações acerca da segurança do vírus vacinal 17D, particularmente quando se identifica que diferentes mecanismos da imunidade podem influenciar o potencial protetor da vacina em hospedeiros considerados imunocompetentes. Por fim, parece que o grande desafio enfrentado pelas agências sanitárias para que se continue mantendo a febre amarela urbana sob controle reside em algumas medidas: 1) combate ao vetor, dificultado pelo crescimento desordenado das cidades na atualidade; 2) desenvolvimento de pesquisas mais profundas acerca de possíveis reações adversas graves para os vacinados e 3) desenvolvimento de uma nova vacina que seja tão potente quanto a existente e mais segura para os hospedeiros imunizados (menos reatogênica).

\section{Referências}

1. Vigilância Epidemiológica. Manual de Vigilância Epidemiológica da Febre Amarela. Brasília: Ministério da Saúde: Fundação Nacional de Saúde, 1999

2. Ministério da Saúde. Febre Amarela. Disponível em: www.saude.gov.br. Acesso em 30 out. 2008.

3. Vasconcelos PFC. Febre amarela: reflexões sobre a doença, as perspectivas para 0 século XXI e 0 risco da reurbanização. Rev Bras Epidemiol. 2002;5(3):244-58

4. Albuquerque BC. Febre Amarela. In: Tavares W, Marinho LAC. Rotinas de Diagnóstico e Tratamento das Doenças Infecciosas e Parasitárias. $2^{\mathrm{a}}$ ed. São Paulo: Atheneu; 2007. p. 403-8.

5. Guia de Vigilância Epidemiológica. Manual de Vigilância Epidemiológica Normas e Manuais Técnicos, $6^{a}$ ed. Brasília: Ministério da Saúde; Fundação Nacional de Saúde; 2005.

6. Romanos MTV. Febre Amarela e Dengue. In: Santos NOS, Romanos MTV, Wigg MD. Introdução à Virologia Humana. Rio de Janeiro: Guanabara Koogan; 2002. p. 177-82.

7. Pinheiro FP, Moraes MAP. Febre amarela. In: Neves J. Diagnóstico e Tratamento das Doenças Infecciosas e Parasitárias. Rio de Janeiro: Guanabara Koogan; 1984.

8. Vasconcelos PFC. Febre Amarela. Rev Soc Bras Med Trop. 2003;36(2): 275-93

9. Monath TP. Yellow fever: An update. Lancet Infectious Diseases. 2001;1: 11-20.
10. Santos F. Dosagem dos fatores da coagulação na febre amarela. Tese (Doutorado), Universidade Federal do Rio de Janeiro, Rio de Janeiro, 1973.

11. Vasconcelos PFC. Febre amarela. Rio de Janeiro: Sociedade Brasileira de Pediatria; 2000.

12. Quaresma JAS, Duarte MIS, Vasconcelos PFC. Midzonal lesions in yellow fever: a specific pattern of liver injury caused by direct virus action and in situ inflammatory response. Med Hypotheses. 2006;67(3):618-21.

13. Quaresma JAS, Barros VLRS, Pagliari C, Fernandes ER, Guedes F, Takakura $\mathrm{CFH}$, et al. Revisiting the liver in human yellow fever: Virus-induced apoptosis in hepatocytes associated with TGF- $\beta$, TNF- $\alpha$ and NK cells activity. Virology. 2006;345:22-30.

14. Quaresma JAS, Barros VLRS, Pagliari C, Fernandes ER, Andrade Jr HF, Vasconcelos PFC, et al. Hepatocyte lesions and cellular immune response in yellow fever infection. Trans Royal S Trop Med Hyg. 2007;101:161-8.

15. Teixeira LA. Datransmissão hídricaa culicidiana: a febre amarelana sociedade de medicina e cirurgia de São Paulo. Rev Bras Hist. 2001;21(41):217-42.

16. Fiocruz. Uma breve história de Febre Amarela. Disponível em: http://www. fiocruz.br/ccs/cgi/cgilua.exe/sys/start.htm?infoid $=1490 \&$ sid $=98 t p l=$ rint ervie. Acesso em 25 mar. 2010.

17. Benchimol JL. História da Febre Amarela no Brasil. Hist cienc saudeManguinhos. 1994;1(1):121-4.

18. Monath TP. 0 desafio da Febre Amarela. In: Quadros CA. Vacinas. São Paulo: Roca; 2008. p. 67-76. 
19. Minas faz ciência. Dengue. Disponível em: http://revista.fapemig.br/ materia.php?id=212. Acesso em 4 ago. 2009.

20. World Health Organization. Yellow fever vaccine. 200340:349-60. Disponível em: www.who.int/wer.

21. Santos-Torres S, Straatmann A, Mota K, Vaconcelos PFC, Rosa APAT, Tavares-Neto J. Estado imune contra 0 vírus vacinal (17D) da febre amarela em duas populações do Estado da Bahia. Rev Soc Bras Med Trop. 2000;33(1):39-46.

22. Superintendência de Campanhas de Saúde Pública. Manual de vacinação antiamarílica: instruções para vacinadores. Brasília: Ministério da Saúde; 1987.

23. Guerra HL, Sardinha TM, Rosa APAT, Lima e Costa MF. Efetividade da vacina antiamarílica 17D: uma avaliação epidemiológica em serviços de saúde. Rev Panam Salud Publica/Pan Am J Public Health. 1997;2(2): 115-20.

24. Pinheiro FP, Gomes ML, Oliva OP. Immune response to yellow fever vaccine. In: Organização Pan-Americana da Saúde. Symposium on yellow fever. Belém: OPAS; 1980.

25. Barrett $A D$, Teuwen DE. Yellow fever vaccine - how does it work and why do rare cases of serious adverse events take place? Curr Opin Immunol. 2009;21(3):308-13.

26. Martins MA, Silva ML, Marciano APV, Elói-Santos SM, Magalhães VP, Ribeiro, JGL, et al. Activation/modulation adaptative immunity emerges simultaneously after $17 \mathrm{DD}$ yellow fever first-time vaccination: is this the key to prevent severe adverse reactions following immunization? Clin Exp Immunol. 2007;148(1):90-100.

27. Miller JD, van der Most RG, Glidewell JT, Albott S, Masopust D, MuraliKrishna $\mathrm{K}$, et al. Human effector and memory CD8 $+\mathrm{T}$ cell responses to smallpox and yellow fever vaccines. Immunity. 2008;28(5):710-22.

28. Querec T, Bennnouna S, Alkan S, Laouar Y, Gorden K, Flavell R, et al. Yellow fever vaccine YF-17D actives multiple dendritic cell subsets via TLR2, 7, 8, and 9 to stimulate polyvalent immunity. J Exp Med. 2006;203(2): 413-24.

29. Santos AP, Matos DC, Bertho AL, Mendonça SC, Marcovistz R. Detection of Th1/Th2 cytokine signature in yellow fever 17DD first-time vaccinees through ELISpot assay. Cytokine. 2008;42(2):152-5.

30. Martins MA, Silva ML, Elói-Santos SM, Ribeiro JGL, Magalhães VP, Marciano APV, et al. Innate immunity phenotypic features point toward simultaneous raise of activation and modulation events following 17DD live attenuated yellow fever first-time vaccination. Vaccine. 2008;26(9): 1173-84.

31. Nishioka Sde A, Nunes-Araújo FR, Pires WP, Silva FA, Costa HL. Yellow fever vaccination during pregnancy and spontaneous abortion: a casecontrol study. Trop Med Int Health. 1998;3(1):29-33.

32. Hayes EB. Acute viscerotropic disease following vaccination against yellow fever. Trans R Soc Trop Med Hyg. 2007;101(10):967-71.

33. Vasconcelos PFC, Bryant JE, Travassos da Rosa APA, Tesh RB, Rodrigues SG, Barrett ADT. Genetic Divergence and Dispersal of Yellow Fever Virus, Brazil. Emerging Infectious Diseases. 2004;10(9):1578-84.

34. Engel AR, Vasconcelos PFC, McArthur MA, Barrett ADT. Characterization of a viscerotropic yellow fever vaccine variant from a patient in Brazil. Vaccine. 2006;24(15):2803-9.

35. Galler R, Pugachev KV, Santos CLS, Ocran SW, Jabor AV, Rodrigues SG, et al. Phenotypic and molecular analyses of yellow fever $17 D D$ vaccine viruses associated with serious adverse events in Brazil. Virology. 2001; 290(2):309-19.

36. Mota LMH, Oliveira ACV, Lima RAC, Santos-Neto, LL, Tauil PL. Vacinação contra febre amarela em pacientes com diagnósticos de doenças reumáticas, em uso de imunossupressores. Rev Soc Br Med Trop. 2009;42(1):23-7. 